\title{
VULNERABILIDADE E ESPAÇO URBANO: MEDIDAS PARA A DESCONSTITUIÇÃO DOS OBSTÁCULOS URBANOS NO CERNE DA LEI N. 13.146, DE 6 DE JULHO DE 2015, DE INCLUSÃO DA PESSOA COM DEFICIÊNCIA
}

\author{
VULNERABILIDAD Y ESPACIO URBANO: MEDIDAS PARA LA \\ DESCONSTITUCIÓN DE LOS OBSTÁCULOS URBANOS EN EL SENO DE LA \\ LEY N. 13.146/2015, DE INCLUSIÓN DE LAS PERSONAS CON DISCAPACIDAD
}

\author{
${ }^{1}$ Paulla Christianne da Costa Newton \\ ${ }^{2}$ Ludmila Albuquerque Douettes Araújo
}

\section{RESUMO}

As pessoas com deficiência padecem abusos e violações em maiores proporções, inclusive de forma institucionalizada, que por vezes são imperceptíveis. Ademais do debate social, diversas questões jurídicas, algumas inclusive ainda pendentes de efetivação, permeiam a realidade social, como é o caso da vulnerabilidade das pessoas com deficiência no espaço urbano. O estudo objetiva identificar os principais óbices urbanos pertinentes ao pleno exercício dos basilares direitos pelas pessoas com deficiência, apontando causas e reflexos para a vida dessas pessoas, examinando os principais instrumentos de tutela consagrados nos corpos normativos internacionais e no ordenamento jurídico pátrio.

Palavras-chave: Inclusão, Pessoas com deficiência, Espaço urbano

\section{RESUMEN}

Las personas con discapacidad siempre han padecido con abusos y violaciones en proporción considerable, incluso de manera institucionalizada e imperceptible. Además del debate social, una gama de cuestiones jurídicas siguen pendientes, como la vulnerabilidad del colectivo en el ámbito de las ciudades. La presente investigación tiene como obyecto la identificación de los principales estorbos en el medio urbano para el ejercicio de los derechos fundamentales del colectivo de personas con discapacidad, dibujándose las medidas, políticas y normas de tutela en el seno de los documentos y convenios internacionales y en el ordenamiento jurídico nacional.

Palabras claves: Inclusión, Discapacidad, Ciudades

\footnotetext{
${ }^{1}$ Doutora em Derecho del Trabajo y Seguridad Social pela Universidade de Valencia - UV, Valencia (Espanha). Professora pela Universidade Estadual da Paraíba - UEPB, Paraíba (Brasil). E-mail: paulla.newton@gmail.com

${ }^{2}$ Doutora em Direito Civil pela Universidad de Granada - UGR, Granada (Espanha). Vice-Diretora do Centro de Ciências Jurídicas pela Universidade Estadual da Paraíba - UEPB, Paraíba (Brasil). E-mail: douettes@ hotmail.com
} 


\section{A TÍTULO DE INTROITO}

A presente pesquisa justifica-se sob os enlaces da vulnerabilidade que envolvem as pessoas com deficiência. Se, por um lado, o fato de ser deficiente apresenta-se como um fator inveterado de vulnerabilidade e discriminação, por outro aspecto a deficiência induz à inserção de outros elementos com idêntica conotação discriminatória.

As pessoas com deficiência padecem abusos e violações em maiores proporções, ao comparar-se às pessoas sem deficiência. Isto se deve aos estigmas de inferioridade e menor valia que as perseguem no contexto da sociedade, como também ao temor que vivenciam com relação a denunciarem possíveis violações de seus direitos e ao descrédito que as eventuais revelações possam receber ${ }^{1}$. Ademais, um complicador resta evidenciado quando a violência e os abusos ocorrem institucionalmente, no seio da família, com os cuidadores, em templos, hospitais, clínicas para tratamento, habilitação e reabilitação, entre outros, tornando-se, efetivamente, uma violência institucionalizada, camuflada pela invisibilidade.

Acrescenta-se a tudo isto a certeza de que a vulnerabilidade agudiza-se quando presentes outras circunstâncias e variantes que, simultaneamente associadas, sedimentam uma maior probabilidade de exclusão social.

O objetivo central do texto é identificar os principais óbices urbanos pertinentes ao pleno exercício dos basilares direitos pelas pessoas com deficiência, apontando causas e reflexos para a vida dessas pessoas, examinando os essenciais instrumentos de tutela consagrados nos corpos normativos internacionais e no ordenamento jurídico pátrio.

Adota-se o método bibliográfico para a compreensão da problemática proposta, partindo-se da literatura jurídica existente sobre a temática. A abordagem foi qualitativa com o emprego de dedução.

Para tanto, utiliza-se uma proposta metodológica baseada na análise de instrumentos normativos relevantes, no seio da sociedade internacional, como a Convenção sobre os Direitos das Pessoas com Deficiência e seu Protocolo Facultativo, homologados pela Assembleia das Nações Unidas em 13 de dezembro de 2006, na Sede das Nações Unidas em Nova York e do exame dos preceitos normativos de tutela às pessoas com deficiência, configurados no ordenamento jurídico pátrio no cerne da Lei n. 13.146, de 6 de julho de 2015,

1 IGLESIAS PADRÓN, Marita. The nature of violence against disabled people. Em: Violence Against People With Disabilities: Seminar Proceedings. National Disability Authority, Dublin, 29 de novembro de 2004. Disponível em:http://www.nda.ie/cntmgmtnew.nsf/0/BE967D49F3E2CD488025707B004C4016?. Acesso em: 22 de setembro de 2015. 
que institui a lei brasileira de inclusão da pessoa com deficiência, considerando-se os aspectos urbanísticos para a plena efetivação dos direitos fundamentais do coletivo anteriormente citado.

A análise apresentada bifurca-se em duas partes. Preliminarmente, o exame dos direitos fundamentais preconizados no bojo da Convenção sobre os Direitos das Pessoas com Deficiência e seu Protocolo Facultativo, homologados pela Assembleia das Nações Unidas em 13 de dezembro de 2006, como elementos inspiradores ao ordenamento jurídico pátrio de tutela aos direitos das pessoas com deficiência. E, em um segundo momento, procederemos a uma abordagem específica sobre os instrumentos de proteção às pessoas com deficiência e os mecanismos para a eliminação dos óbices à efetiva consecução dos direitos fundamentais no espaço urbano, apresentados no âmago da Lei n. 13.146, de 6 de julho de 2015.

De esta forma, vislumbra-se a possibilidade de explorar-se uma gama de hipóteses complexas de vulnerabilidade, as quais podem aderir vários estigmas agressivos, tradicionalmente perpetuados no convívio social.

A exclusão prepondera quando os fatores de discriminação incrementam-se na própria vivência cotidiana das pessoas com deficiência, quer em suas relações familiares ou em seus vínculos sociais, profissionais ou culturais estabelecidos no seio das cidades, em suas amarrações de concreto e aço, tão necessárias quanto excludentes. Neste sentido, eis, pois, o texto que os apresentamos.

\section{FUNDAMENTOS DE TUTELA AOS DIREITOS FUNDAMENTAIS NA} PERSPECTIVA DA CONVENÇÃO DA ORGANIZAÇÃO DAS NAÇÕES UNIDAS SOBRE OS DIREITOS DAS PESSOAS COM DEFICIÊNCIA E SEU PROTOCOLO FACULTATIVO

A Convenção sobre os Direitos das Pessoas com Deficiência e seu Protocolo Facultativo, homologados pela Assembleia das Nações Unidas em 13 de dezembro de 2006, preconiza o tratamento diferenciado, reconhecendo, em seu preâmbulo, os documentos internacionais de tutela aos direitos fundamentais e às minorias em risco de exclusão, como o Pacto Internacional dos Direitos Econômicos, Sociais e Culturais, o Pacto Internacional dos Direitos Civis e Políticos, a Convenção Internacional sobre a Eliminação de Todas as Formas de Discriminação Racial, a Convenção sobre a Eliminação de todas as Formas de Discriminação contra a Mulher, a Convenção contra a Tortura e Outros Tratamentos ou Penas Cruéis, Desumanos ou Degradantes, a Convenção sobre os Direitos da Criança e a Convenção 
Internacional sobre a Proteção dos Direitos de Todos os Trabalhadores Migrantes e Membros de suas Famílias.

Daí reconhecer, desde a parte introdutória do texto pactuado, a condição de vulnerabilidade das pessoas com deficiência, no intuito de elucidar os perfis norteadores da interpretação, direcionamento e integração do texto convenido.

As linhas mestras, preliminarmente dispostas na Convenção, conduzem os convenentes a adequarem as suas práticas, medidas, programas e normativas aos preceitos trazidos no cerne de outros relevantes documentos internacionais, a reverência aos direitos humanos, no respeito à diversidade e a não discriminação, como prelúdio aos mecanismos especificamente previstos. Estas medidas de proteção articulam-se nos seguintes mandamentos:

A) Direito à vida em igualdade de oportunidades com as demais pessoas

O artigo 10 da Convenção sobre os Direitos das Pessoas com Deficiência assinala que todo ser humano tem o direito à vida. Neste sentido, os Estados firmantes incorporarão todas as medidas necessárias para assegurar o efetivo exercício desse direito pelas pessoas com deficiência, em igualdade de oportunidades com as demais pessoas. Destarte, o direito à vida inclui, como inerente, as condições fundamentais à digna vivência em sociedade.

B) Ênfase à eliminação das desigualdades, respeito à diversidade, não-discriminação e à igualdade entre homens e mulheres no contexto dos princípios gerais

Os princípios gerais previstos no art. $3^{\circ}$ da Convenção auspiciam a abordagem de gênero, sublinhando o respeito à não-discriminação, a plena e efetiva participação e inclusão na sociedade, que tão somente poderá efetivar-se com a extirpação das desigualdades e a convivência cordata com as diferenças porventura existentes, assim como a estima pela diferença e pela aceitação das pessoas com deficiência como parte da diversidade humana e da humanidade.

Diante do exposto, comprova-se que o documento pactuado prioriza, em seus princípios reitores, o apreço pela igualdade, não discriminação, diversidade e inclusão.

C) Respeito ao casamento, aos relacionamentos, à constituição do lar e da família

A Convenção sobre os Direitos das Pessoas com Deficiência estabelece, em seu artigo 23, a adoção de medidas efetivas e adequadas para eliminar a discriminação contra as pessoas com deficiência no que concerne ao casamento, família, paternidade e relacionamentos afetivos. 
Neste aspecto especial, prioriza o reconhecimento do direito das pessoas com deficiência, em idade de contrair matrimônio, de casar-se e estabelecer família, com base no livre e pleno consentimento dos pretendentes, como também o direito de decidirem livre e responsavelmente sobre o número de filhos e o acesso às informações adequadas à idade e a educação em matéria de reprodução e de planejamento familiar.

D) Medidas adequadas para assegurar às pessoas com deficiência o acesso a serviços de saúde, incluindo os serviços de reabilitação

Neste aspecto, a conscientização, sensibilização e capacitação dos profissionais envolvidos na assistência e atenção dos serviços de saúde é fator crucial para a inclusão e proteção aos fundamentais direitos das pessoas com deficiência. Sendo igualmente imprescindível que estes serviços apresentem-se qualificados para atender as necessidades especiais individualizadas, informar sobre as práticas e procedimentos adotados e lidar com temáticas razoavelmente complexas, como aquelas referentes à saúde sexual e reprodutiva.

E) Direito à proteção social

O artigo 28. 2, b, da Convenção sobre os Direitos das Pessoas com Deficiência assegura que os Estados deverão promover medidas adequadas para resguardar e disseminar o exercício pleno do direito à proteção social, extirpando qualquer elemento de discriminação baseado na deficiência que possa obstaculizar o efetivo usufruto dos direitos relacionados a esta proteção. Ademais, a Convenção firma outros direitos de resguardo à proteção social, incluindo o acesso aos serviços de água potável e a dispositivos e assistência de outra índole, a preços acessíveis, para atender às necessidades específicas relacionadas com a deficiência (art. 28, 2 . a); o acesso à assistência do Estado em relação aos gastos ocasionados pela deficiência, incluindo capacitação, assessoramento, auxílio financeiro e serviços temporais adequados para as pessoas com deficiência e suas famílias que estejam em situação de pobreza ( art.28, 2. c ); o acesso das pessoas com deficiência a programas habitacionais públicos ( art.28, 2. d ); o acesso igualitário das pessoas com deficiência a programas e benefícios de aposentadoria ( art.28, 2.e ).

F) Conscientização e sensibilização em relação aos estereótipos

Neste enfoque, a Convenção sobre os Direitos das Pessoas com Deficiência contempla a adoção de medidas para conscientizar e sensibilizar a sociedade no tocante ao respeito aos direitos e à dignidade das pessoas com deficiência, combatendo estereótipos, preconceitos e 
práticas nocivas geralmente associadas a este grupo $\left(\operatorname{art} .8^{\circ}\right)$.

G) Direitos relacionados ao mercado laboral

Previstos no art. 27 da Convenção, inclui: igualdade de oportunidades; liberdade de escolha; ambiente laboral inclusivo e acessível; tutela aos que adquiriram deficiência em razão do trabalho; vedação à discriminação fundamentada na deficiência; proteção contra o assédio e a reparação pelos agravos padecidos; proteção relacionada às condições de trabalho seguras e salubres; garantia do exercício pleno dos direitos trabalhistas e sindicais; possibilitar o acesso efetivo a programas gerais de orientação técnica e vocacional e a serviços de colocação no mercado laboral, assim como formação profissional e continuada; promoção de oportunidades de emprego e ascensão profissional, bem como assistência na procura, obtenção e manutenção do emprego e no retorno ao emprego; fomento do espírito empreendedor, do labor autônomo, de cooperativas e do negócio próprio; emprego no setor público; políticas e medidas para a promoção do emprego no setor privado, incluindo ação afirmativa e incentivos, entre outros ${ }^{2}$.

Prossegue o texto da Convenção, ainda em seu art. 27, para assegurar adaptações razoáveis no local de trabalho e à aquisição de experiência no exercício das atividades, a promoção de programas de reabilitação vocacional e profissional, manutenção do emprego e programas de reinserção laboral e a proteção contra a escravidão, a servidão, o trabalho forçado ou compulsório.

H) Padrão adequado de vida para a pessoa com deficiência e para a sua família

Sob este prisma, a Convenção reverencia à alimentação, vestuário e moradia, salvaguardando a contínua melhoria de suas condições de vida (art.28. 1).

I) Serviços e programas de habilitação e reabilitação

O art.26 da Convenção explicita que os Estados reunirão medidas efetivas e adequadas para que as pessoas com deficiência possam lograr e manter a máxima independência, capacidade física, mental, social e vocacional, e a plena participação e inclusão em todos os aspectos da vida, através da organização, intensificação e ampliação de serviços e programas gerais de habilitação e reabilitação, particularmente, nos âmbitos da saúde, do emprego, da

2 Com respeito à tutela antidiscriminatória das mulheres nas relações laborais, incluindo as mulheres com deficiência, ver significativa construção em NEWTON, Paulla Christianne da Costa. Empleo y sexismo: medidas de protección e inserción sociolaboral de las mujeres víctimas de violencia de género em el seno de la pareja. Valencia: Tirant Lo Blanch, 2011. 
educação e dos serviços sociais.

J) Participação na vida cultural, nas atividades recreativas, lazer e esporte

A Convenção ostenta, em seu artigo 30, o direito das pessoas com deficiência participarem na vida cultural, nas atividades recreativas, no lazer e nos esportes, atendendo a necessidade de construção de medidas que assegurem esta plena inserção.

K) Participação na vida política e pública

Neste aspecto, os Estados Partes devem assegurar a plena e efetiva participação das pessoas com deficiência na vida política e pública, incluindo o direito de votar e ser votado e promover ativamente que possam, efetivamente, participar no direcionamento dos assuntos públicos, fomentando, para tanto, a participação das pessoas com deficiência em organizações e associações não governamentais relacionadas com a vida pública e política do país, incluídas as atividades e a administração dos partidos políticos, como também, a constituição e incorporação em organizações de pessoas com deficiência que as representem internacionalmente, nacionalmente, regionalmente e localmente (art.29).

L) Outros direitos e garantias efetivamente assecuratórios da participação inclusiva na sociedade ${ }^{3}$

Nesta perspectiva, a Convenção prioriza a autonomia e a independência através de mecanismos de acessibilidade que assegurem as pessoas com deficiência a maior integração com o seu entorno físico, os transportes, a informação e as comunicações, aos serviços e instalações abertas ao público ou de uso público, nas zonas urbanas e rurais (art. 9) ${ }^{4}$; a garantia de acesso adequado à justiça (art.13); o direito de viver de forma independente, de conviver e participar da comunidade (Art.19) e medidas para assegurar a mobilidade pessoal

3 Neste patamar, merece destaque algumas legislações sedimentadas em solo pátrio que beneficiam as pessoas com deficiência: Lei $\mathrm{n}^{\circ}$ 8.213, de 24 de junho de 1991, reserva em empresas e vagas em concurso público; Lei $\mathrm{n}^{\circ}$ 10.182, 12 de fevereiro de 2001, sobre a isenção de impostos para a aquisição de veículos; Lei no 10.226, de 15 de maio de 2001, sobre os locais de votação; Lei no 10.436, de 24 de abril de 2002, dispõe sobre a adoção da língua brasileira de sinais nos cursos de formação em Educação Especial, Fonoaudiologia e Magistérios e Lei $n^{\circ}$ 11.096, de 13 de janeiro de 2005, que estabelece o Programa Universidade para Todos - PROUNI, entre outras. 4 A Pesquisa de Informações Básicas Municipais 2009 (MUNIC) indica que 29,2\% dos municípios brasileiros consideram os critérios de acessibilidade quando da realização de concessão, permissão ou autorização para a exploração dos serviços de transporte coletivo por ônibus intramunicipal. Deste índice, 76,7\% concentra-se nas Regiões Sudeste e Sul. Ver BRASIL. Ministério do Planejamento, Orçamento e Gestão. Instituto Brasileiro de Geografia e Estatística-IBGE. Diretoria de Pesquisas. Coordenação de População e Indicadores Sociais. Pesquisa de Informações Básicas Municipais. Perfil dos Municípios Brasileiros 2009. Rio de Janeiro, 2010. Relatório MUNIC 2009. Disponível em: http://www.ibge.gov.br/home/. Acesso em: 21 de setembro de 2015. 
com a maior independência possível (Art.20) ${ }^{5}$.

Conforme o exposto, depreende-se que o texto da Convenção prima pela consolidação de normas, políticas e medidas de tutela de proteção integral em vários âmbitos e perspectivas, com a eliminação de potenciais obstáculos sociais, culturais e urbanísticos que obstaculizam o exercício pleno das garantias fundamentais.

\section{A DESCONSTRUÇÃO DAS BARREIRAS URBANÍSTICAS NA LEI N.}

\subsection{6, DE 6 DE JULHO DE 2015, QUE INSTITUI A LEI BRASILEIRA DE INCLUSÃO DA PESSOA COM DEFICIÊNCIA}

\subsection{Os óbices à consecução e plena efetividade dos direitos fundamentais das} pessoas com deficiência em razão das barreiras urbanísticas e outros entraves

O art. $1^{\circ}$ da Lei n. 13.146, de 6 de julho de 2015, enfatiza que o Estatuto da Pessoa com Deficiência tem como objetivo assegurar e promover o exercício dos direitos e das liberdades fundamentais, visando à inclusão social e o pleno exercício da cidadania da pessoa com deficiência. O corpo normativo em comento fundamenta-se na Convenção sobre os Direitos das Pessoas com Deficiência e seu Protocolo Facultativo, ratificados pelo Congresso Nacional por meio do Decreto Legislativo $\mathrm{n}^{0} 186$, de 9 de julho de 2008 , em vigor para o Brasil, no plano jurídico externo, desde 31 de agosto de 2008, e promulgados pelo Decreto $\mathrm{n}^{\mathrm{o}}$ 6.949, de 25 de agosto de 2009, data de início de sua vigência no plano interno.

Em termos conceituais, ao utilizarmos as noções do Estatuto da Pessoa com Deficiência, podemos considerar como tal,

aquela que tem impedimento de longo prazo de natureza física, mental, intelectual ou sensorial, o qual, em interação com uma ou mais barreiras, pode obstruir sua participação plena e efetiva na sociedade em igualdade de condições com as demais pessoas.

Por sua vez, a pessoa com mobilidade reduzida é,

aquela que tenha, por qualquer motivo, dificuldade de movimentação, permanente ou temporária, gerando redução efetiva da mobilidade, da flexibilidade, da coordenação motora ou da percepção, incluindo idoso, gestante, lactante, pessoa com criança de colo e obeso $\left(\operatorname{art} .2^{\circ}\right.$ e $\operatorname{art} .3^{\circ}$, IX).

Todos os ambientes urbanísticos devem ser consolidados compreendendo-se a

5 Ver o Decreto $\mathrm{n}^{\circ} 5.296$,de dezembro de 2004, que regulamentou as Leis $\mathrm{n}^{\circ} 10.048 / 2000$ e $\mathrm{n}^{\circ}$ 10.098/2000, trata de acessibilidade para as pessoas com deficiência ou com mobilidade reduzida (idosos, gestantes, obesos, pessoas com criança de colo) e representa o passo decisivo para a cidadania destas. 
necessidade de adaptação, interação e integração das pessoas ao meio em que vivem. Desta forma, não se pode constituir o urbano, apartando-se dos preceitos de tutela às pessoas com deficiência e às pessoas com mobilidade reduzida. Olvidar-se dos coletivos vulneráveis na edificação dos espaços urbanos é obscurecer a condição de pessoa humana a estes grupos, negando-lhes o acesso às estruturas de moradia, lazer, ócio, trabalho e relações sociais.

Deve figurar como inerente às projeções urbanísticas pensar-se o Direito à acessibilidade. Nos termos da lei de inclusão, tal direito consiste na,

possibilidade e condição de alcance para utilização, com segurança e autonomia, de espaços, mobiliários, equipamentos urbanos, edificações, transportes, informação e comunicação, inclusive seus sistemas e tecnologias, bem como de outros serviços e instalações abertos ao público, de uso público ou privados de uso coletivo, tanto na zona urbana como na rural, por pessoa com deficiência ou com mobilidade reduzida $\left(\operatorname{art.}^{\circ}, \mathrm{I}\right)$.

Ou seja, a acessibilidade conduz aos paradigmas mestres para a sedimentação da efetiva integração do deficiente, qualquer que seja a sua limitação, à vida urbana e à utilização dos espaços públicos.

A Constituição Federal de 1988 preconiza às máximas garantias aos fundamentais direitos de todas as pessoas, difundidos, aclamados e consagrados, seja no cerne do seu art. $5^{\circ}$, seja em outros preceitos incorporados ao ordenamento constitucional vigente. Entre os quais podemos destacar a dignidade da pessoa humana, a igualdade, as liberdades, o direito de expressão, o direito de informação, de forma ilustrativa. Para a consecução de tais direitos, há que se considerar que qualquer entrave ao usufruto de tais direitos deverá ser eliminado.

A Lei 13.146, em seu art. $8^{\circ}$, preconiza como dever do Estado, da sociedade e da família assegurar à pessoa com deficiência, prioritariamente, a efetivação dos direitos referentes à vida, à saúde, à sexualidade, à paternidade e à maternidade, à alimentação, à habitação, à educação, à profissionalização, ao trabalho, à previdência social, à habilitação e à reabilitação, ao transporte, à acessibilidade, à cultura, ao desporto, ao turismo, ao lazer, à informação, à comunicação, aos avanços científicos e tecnológicos, à dignidade, ao respeito, à liberdade, à convivência familiar e comunitária, entre outros decorrentes da Constituição Federal, da Convenção sobre os Direitos das Pessoas com Deficiência e seu Protocolo Facultativo e das leis e de outras normas que garantam seu bem-estar pessoal, social e econômico.

Sendo assim, a pessoa com deficiência tem direito à igualdade de oportunidades com as demais pessoas, não podendo padecer nenhum tipo de discriminação ou restrição aos seus direitos por fato da deficiência.

Neste particular, compreendem-se como óbices, obstáculos ou barreiras 
qualquer entrave, obstáculo, atitude ou comportamento que limite ou impeça a participação social da pessoa, bem como o gozo, a fruição e o exercício de seus direitos à acessibilidade, à liberdade de movimento e de expressão, à comunicação, ao acesso à informação, à compreensão, à circulação com segurança, entre outros ${ }^{6}$.

Essas barreiras, impedientes da efetiva consolidação dos direitos fundamentais da pessoa com deficiência podem ser classificadas em categorias ${ }^{7}$, as quais passamos a explanar.

Preliminarmente, faz-se referência as barreiras urbanísticas, que correspondem àquelas existentes nas vias e ou nos espaços públicos e privados abertos ao público ou de uso coletivo. Tais obstáculos constituem elemento excludente no ambiente de uso coletivo e que, deveria ser acessível a todos, independentemente de qualquer fator de vulnerabilidade. As pessoas com deficiência encontrar-se-ão excluídas de tais espaços urbanos, ilustrativamente, quando não existem rampas nas calçadas, semáforos adaptados à diversidade de deficiências existentes, portas e pontes estreitas, entre outros.

O outro tipo de óbice destacado são as chamadas barreiras arquitetônicas que, qualificam-se como as existentes nos edifícios públicos e privados. Exemplificativamente, podemos ilustrar com as dificuldades enfrentadas pelos deficientes pela não elaboração das construções, de forma a atender às diversas modalidades de deficiência, como a ausência de rampas ou mecanismos eletromecânicos de acesso aos andares de um prédio, ausência de banheiro adaptado, sinais sonoros e outros tipos similares de alerta para situações de emergência, entre outros.

A terceira barreira é aquela existente nos sistemas e meios de transportes. A ausência de adaptações razoáveis nos meios de transportes ou a presença de mecanismos de apoio defeituosos ou com informações inadequadas sobre o uso, obstaculizam o basilar direito de ir e vir aos cidadãos com mobilidade reduzida.

As barreiras nas comunicações e na informação consistem em qualquer entrave, obstáculo, atitude ou comportamento que dificulte ou impossibilite a expressão ou o recebimento de mensagens e de informações por intermédio de sistemas de comunicação e de tecnologia da informação. Neste aspecto, podemos sublinhar a ausência de sinais visuais, lumínicos ou auditivos em centros comerciais, ambientes públicos ou privados, para identificar espaços, ambientes ou pontos cruciais ao transeunte.

E ainda no meio urbano, cabe enfatizar o protagonismo pernicioso das cognominadas barreiras atitudinais, correspondentes às atitudes ou comportamentos que obstaculizem ou dificultem a participação social da pessoa com deficiência em igualdade de condições e

6 Vide art.3ํㅡㄴ, IV, da lei n.13.146, de 6 de julho de 2015.

7 Vide art.3ํำ , IV, da lei n.13.146, de 6 de julho de 2015. 
oportunidades com as demais pessoas. Seguramente, esta barreira é a raiz de todas as outras, posto que é a tradicional exclusão das pessoas vulneráveis o principal fundamento para a constituição de tantos fatores impeditivos da efetiva integração do deficiente ao meio urbano.

Estas barreiras atitudinais destacam-se pelo comportamento, práticas e atos de desrespeito, exclusão, discriminação e rechaço às pessoas com deficiência, de forma consciente ou não. Por exemplo, citemos o estacionamento indevido de automóvel em vaga reservada, o bloqueio do piso tátil direcional, as atitudes de discriminação, repúdio e até mesmo asco com os deficientes, entre outras reprováveis atitudes tão presentes em nossas cidades.

\subsection{Medidas e institutos para a plena integração aos espaços urbanos}

Antes da análise das medidas e projeções para a adequação do espaço urbano aos fundamentais direitos das pessoas com deficiência, cabe tecer alguns comentários sobre o repúdio às barreiras obstativas da inserção no meio urbano do coletivo em comento.

Primeiramente, há que se excluir às barreiras atitudinais, com esforços, medidas e programas direcionados ao âmbito educacional. Indubitavelmente, a educação inclusiva, interativa e integrativa, com a participação efetiva das pessoas com deficiência em todos os níveis e escalas do sistema educacional institucionalizado, constitui fator essencial ao extermínio das tradicionais formas de discriminação que o coletivo habitualmente padece.

O pilar fundamental para a eliminação das demais barreiras, urbanísticas, arquitetônicas, nos transportes e comunicacionais que, dificultam o convívio urbano das pessoas com deficiência é a proposta educativa direcionada ao respeito às diferenças e à convivência com a vulnerabilidade, interpretando-se as singularidades como elementos que transformam cada ser humano em um ser único e especial e não como fator excludente e vexatório. E, para tanto, cabe a qualificação de profissionais habilitados e equipe multiprofissional especializada para compor programas, medidas e uma estrutura pedagógica adequada ao perfil dos grupos vulneráveis e em risco de exclusão social, desde os níveis iniciais da educação básica.

Segundo o VI Relatório Nacional Brasileiro, de 2008, continuam sendo reformulados os "Parâmetros ou Referenciais Curriculares para os diferentes níveis de ensino", com vistas a aperfeiçoar "dentro da política de avaliação e distribuição do livro didático, os critérios 
referentes a gênero, raça, deficiência e etnia"8.

Isto torna-se importante à medida em que as diretrizes para a sensibilização da sociedade sejam fixadas desde o próprio sistema educacional, em seus diferentes níveis.

Sob a perspectiva penal, a Lei n. 13.146, de 6 de julho de 2015, criminaliza, em seu art.88, a prática, indução ou incitação da discriminação de pessoa em razão de sua deficiência, com pena de reclusão de 1 a 3 anos e multa; a pena será aumentada em 1/3 (um terço) se a vítima encontrar-se sob cuidado e responsabilidade do agente e será de 2 a 5 anos, além da multa, se o delito é cometido por intermédio de meios de comunicação social ou de publicação de qualquer natureza.

Com o intuito de rechaçar os óbices existentes no espaço urbano, o texto normativo em comento estabeleceu um leque de institutos, medidas e diretrizes, posteriormente identificadas:

I) Direito de acessibilidade como instrumento imprescindível ao exercício da cidadania substantiva ${ }^{9}$

A acessibilidade é direito essencial à pessoa com deficiência, pois assegura autonomia e meios para o exercício dos direitos de cidadania e de participação social. Sendo assim, a lei de inclusão da pessoa com deficiência obriga o cumprimento das normas relativas à acessibilidade, compreendendo-se:

A - a aprovação de projeto arquitetônico e urbanístico ou de comunicação e informação, a fabricação de veículos de transporte coletivo, a prestação do respectivo serviço e a execução de qualquer tipo de obra, quando tenham destinação pública ou coletiva;

B - a outorga ou a renovação de concessão, permissão, autorização ou habilitação de qualquer natureza;

C - a aprovação de financiamento de projeto com utilização de recursos públicos, por meio de renúncia ou de incentivo fiscal, contrato, convênio ou instrumento congênere;

D - a concessão de aval da União para obtenção de empréstimo e de financiamento internacionais por entes públicos ou privados.

Assim, para a elaboração e a implantação de projetos que tratem do meio físico, de transporte, de informação e comunicação, inclusive de sistemas e tecnologias da informação e

\footnotetext{
8 BRASIL. VI Relatório Nacional Brasileiro. Convenção para a Eliminação de todas as formas de Discriminação contra as Mulheres (CEDAW) - Organizações das Nações Unidas. Secretaria Especial de Políticas para as Mulheres. Brasília, 2008, página 169. Disponível em: http://www.sepm.gov.br/publicacoesteste/publicacoes/2008/livrocedawweb.pdf. Acesso em: 21 de setembro de 2015.

9 Vide do art.53 ao art.62, da lei n.13.146, de 6 de julho de 2015.
} 
comunicação, e de outros serviços, equipamentos e instalações abertos ao público, de uso público ou privado de uso coletivo, tanto na zona urbana como na rural, devem atender aos princípios do desenho universal, tendo como referência as normas de acessibilidade.

O desenho universal será considerado como a regra geral. Por desenho universal deve-se compreender a concepção de produtos, ambientes, programas e serviços a serem usados por todas as pessoas, sem necessidade de adaptação ou de projeto específico, incluindo os recursos de tecnologia assistiva. Ou seja, o desenho universal constitui a projeção ideal para o amparo, indistinto, de todas as pessoas, com deficiência ou não, de forma a atender às necessidades variadas, de forma satisfatória. Por sua vez, a tecnologia assistiva consiste no acesso a produtos, recursos, estratégias, práticas, processos, métodos e serviços que maximizem a autonomia, a mobilidade pessoal e a qualidade de vida da pessoa com deficiência ${ }^{10}$.

A acessibilidade também deve ser adotada para a construção, a reforma, a ampliação ou a mudança de uso de edificações abertas ao público, de uso público ou privada, de uso coletivo, sejam as edificações atuais ou as futuras.

As regras de acessibilidade também orientarão os planos diretores municipais, os planos diretores de transporte e trânsito, os planos de mobilidade urbana e os planos de preservação de sítios históricos, os códigos de obras, os códigos de postura, as leis de uso e ocupação do solo e as leis do sistema viário, os estudos prévios de impacto de vizinhança, as atividades de fiscalização e a imposição de sanções e a legislação referente à prevenção contra incêndio e pânico.

A Lei $\mathrm{n}^{\mathrm{o}}$ 10.257, de 10 de julho de 2001, que regulamenta os artigos 182 e 183 da Constituição Federal de 1988, para estabelecer diretrizes gerais da política urbana, no $\S 3^{\circ}$, do art. 41, consagra que as cidades devem elaborar plano de rotas acessíveis, compatível com o plano diretor no qual está inserido, que disponha sobre os passeios públicos a serem implantados ou reformados pelo poder público, com vistas a garantir acessibilidade da pessoa com deficiência ou com mobilidade reduzida a todas as rotas e vias existentes, inclusive as que concentrem os focos geradores de maior circulação de pedestres, como os órgãos públicos e os locais de prestação de serviços públicos e privados de saúde, educação, assistência social, esporte, cultura, correios e telégrafos, bancos, entre outros, sempre que possível de maneira integrada com os sistemas de transporte coletivo de passageiros.

10 Cf. art.74, da Lei n.13.146, de 6 de julho de 2015. 
II) Direito à moradia digna, adequada e organizada às necessidades e autonomia

A autonomia e independência pressupõem condições dignas e adequadas de moradia. Neste sentido, a Lei n. 13.146 consagra em seu art. 31 que a pessoa com deficiência tem direito à moradia digna, tanto no seio de sua família, como em moradia para a vida independente ou em residência inclusiva.

A pessoa com deficiência ou seu responsável goza de prioridade na aquisição de imóvel para moradia própria, nos programas habitacionais públicos ou subsidiados, com a reserva de, no mínimo, 3\% (três por cento) das unidades habitacionais, assegurando-se à acessibilidade nas áreas de uso comum e a disponibilização de equipamentos urbanos comunitários acessíveis. O direito à prioridade será reconhecido ao beneficiário apenas uma vez $^{11}$.

Desta forma, torna-se imprescindível que as residências encontrem-se adequadas às necessidades variadas pertinentes às deficiências. Caso contrário, o intuito maior do legislador não estará sendo adimplido.

Com relação às estruturas residenciais, o Estatuto disponibiliza dois níveis específicos de tutela para a melhoria da acomodação familiar da pessoa com deficiência. Neste patamar, cabe ressaltar a existência das chamadas residências inclusivas e as moradias adequadamente estruturadas para assegurar à autonomia da pessoa com deficiência ${ }^{12}$.

As residências inclusivas consolidam-se como unidades de oferta do Serviço de Acolhimento do SUAS - Sistema Único de Assistência Social. Tais residências localizadas devem contar com adequação estrutural ao atendimento essencial das necessidades básicas de conforto e comodidade.

A segunda espécie de tutela específica direciona-se à moradia para a vida independente da pessoa com deficiência, destacando-se que a residência deve manter estruturas adequadas, aptas a proporcionarem serviços de apoio coletivos e individualizados que respeitem e ampliem o grau de autonomia das pessoas com deficiência.

III) Direito à adequação dos espaços para a consecução de educação de qualidade

A educação constitui, simultaneamente, direito da pessoa com deficiência e dever do Estado, da família, da comunidade escolar e da sociedade. Desta forma, o sistema educacional inclusivo deve ser consagrado em todos os níveis e de forma continuada, com vistas ao desenvolvimento das vocações e habilidades físicas, sensoriais, intelectuais e sociais da 
pessoa com deficiência, considerando-se as suas características, interesses e necessidades de aprendizagem.

Para isto, deve-se conceber modelos de acessibilidade que maximizem o desenvolvimento acadêmico e social dos estudantes com deficiência, favorecendo o acesso, a permanência, a participação e a aprendizagem em instituições de ensino ${ }^{13}$.

No cerne dos estabelecimentos educacionais, a Lei de inclusão dispõe sobre a assistência do cognominado profissional de apoio escolar, tratando-se de auxiliar da pessoa com deficiência, para coadjuvar nas atividades de alimentação, higiene e locomoção e nas atividades escolares, em todos os níveis educacionais e modalidades de ensino, em instituições públicas e privadas ${ }^{14}$.

IV) Direito ao ambiente de trabalho inclusivo e acessível ${ }^{15}$

A pessoa com deficiência tem direito ao trabalho em ambiente acessível e inclusivo, em igualdade de oportunidades com as demais pessoas. Sendo assim, as instituições empregadoras obrigam-se a assegurarem ambientes de trabalho acessíveis e inclusivos, atentando-se sempre às regras de acessibilidade, o fornecimento de recursos de tecnologia assistiva e a adaptação razoável no ambiente de trabalho ${ }^{16}$.

Um caso especial de tutela ao trabalho das pessoas com deficiência no ambiente das cidades, refere-se ao art. 12-B da Lei $\mathrm{n}^{\mathrm{o}}$ 12.587, de 3 de janeiro de 2012, incluído pela Lei 13.146, de 2015, ao preconizar que na outorga de exploração de serviço de táxi, reservar-se-ão $10 \%$ (dez por cento) das vagas para condutores com deficiência, observando-se que o veículo utilizado seja de sua propriedade e por ele conduzido e esteja adaptado às suas necessidades.

V) Direito à cultura, ao esporte, ao turismo e ao lazer

A lei de inclusão consagra o direito ao lazer e às atividades culturais para as pessoas com deficiência, em igualdade de oportunidades com as demais pessoas, garantindo-se, sempre, o acesso a bens culturais, a programas de televisão, cinema, teatro e outras atividades culturais e desportivas em formato acessível e a monumentos e locais de importância cultural e a espaços que ofereçam serviços ou eventos culturais e esportivos.

Para isto, a administração pública deve adotar soluções destinadas à eliminação, à

13 Vide art.27 e art.28, da Lei n.13.146, de 6 de julho de 2015.

14 Vide art.3, XIII, e art.28, da Lei n.13.146, de 6 de julho de 2015.

15 Sob esta perspectiva vide GORDILLO, Vanessa Cordero. Igualdad y No Discriminación de las Personas con

Discapacidad en el Mercado de Trabajo. "Colección Laboral” 194. Valencia: Tirant Lo Blanch, 2011.

16 Vide art.34 e art.37, da Lei n.13.146, de 6 de julho de 2015. 
redução ou à superação de barreiras para a promoção do acesso a todo patrimônio cultural, observadas as normas de acessibilidade, ambientais e de proteção do patrimônio histórico e artístico nacional $^{17}$.

A participação da pessoa com deficiência será promovida pelo poder público em atividades artísticas, intelectuais, culturais, esportivas e recreativas, com vistas a incentivar a provisão de instrução, de treinamento e de recursos adequados, em igualdade de oportunidades com as demais pessoas; assegurar acessibilidade nos locais de eventos e nos serviços prestados por pessoa ou entidade envolvida na organização das atividades de que trata este artigo e assegurar a participação da pessoa com deficiência em jogos e atividades recreativas, esportivas, de lazer, culturais e artísticas, inclusive no sistema escolar, em igualdade de condições com as demais pessoas ${ }^{18}$.

Sendo assim, deve-se garantir que os monumentos de visitação pública e os pontos turísticos sejam acessíveis e possuam, ademais, sinais indicativos de localização e especificações de informações relevantes, passíveis de serem assimiladas pelos diferentes níveis e gamas de deficiência, sem que nenhum tipo de acréscimo ou valor extraordinário seja por isso cobrado.

Nos teatros, cinemas, auditórios, estádios, ginásios de esporte, locais de espetáculos e de conferências e similares, serão reservados espaços livres e assentos para a pessoa com deficiência, de acordo com a capacidade de lotação da edificação. Esses espaços e assentos em locais diversos, de boa visibilidade, em todos os setores, próximos aos corredores, devidamente sinalizados, evitando-se áreas segregadas de público e obstrução das saídas. Ademais, tais espaços e assentos devem situar-se em locais que garantam a acomodação de, no mínimo, um acompanhante da pessoa com deficiência ou com mobilidade reduzida, resguardado o direito de se acomodar proximamente a grupo familiar e comunitário.

No pertinente às questões de segurança, os teatros, cinemas, auditórios, estádios, ginásios de esporte, locais de espetáculos, de conferências e similares deve haver, obrigatoriamente, rotas de fuga e saídas de emergência acessíveis, a fim de permitir a saída segura da pessoa com deficiência ou com mobilidade reduzida, em caso de emergência ${ }^{19}$.

Os estabelecimentos de hospedagem devem adotar os mecanismos de acessibilidade e a regra do chamado desenho universal ${ }^{20}$.

17 Vide art.42, da Lei n.13.146, de 6 de julho de 2015.

18 Vide art.43, da Lei n.13.146, de 6 de julho de 2015.

19 Vide art.44, da Lei n.13.146, de 6 de julho de 2015.

20 Vide art.45, da Lei n.13.146, de 6 de julho de 2015. 
VI) Direito ao transporte e à mobilidade

Neste particular, a acessibilidade aos serviços de transporte coletivo compreende o transporte terrestre, aquaviário e aéreo, considerando-se como integrantes desses serviços os veículos, os terminais, as estações, os pontos de parada, o sistema viário e a prestação do serviço $^{21}$.

Nas áreas de estacionamento aberto ao público, de uso público ou privado de uso coletivo e em vias públicas, devem ser reservadas vagas próximas aos acessos de circulação de pedestres, devidamente sinalizadas, para veículos identificados que transportem pessoa com deficiência com comprometimento de mobilidade, com credencial válida em todo o território nacional. As vagas devem equivaler a $2 \%$ (dois por cento) do total, garantida, no mínimo, 1 (uma) vaga devidamente sinalizada e com as especificações de desenho e traçado de acordo com as normas técnicas vigentes de acessibilidade. Os veículos estacionados nas vagas reservadas devem exibir, em local de ampla visibilidade, a credencial de beneficiário, a ser confeccionada e fornecida pelos órgãos de trânsito. A utilização indevida das vagas sujeita os infratores às sanções previstas no inciso XVII do art. 181 da Lei $n^{0} 9.503$, de 23 de setembro de 1997, o Código de Trânsito Brasileiro ${ }^{22}$.

Os veículos de transporte coletivo terrestre, aquaviário e aéreo, as instalações, as estações, os portos e os terminais em operação no País devem ser acessíveis, de forma a dispor de sistema de comunicação acessível que disponibilize informações sobre todos os pontos do itinerário, sendo asseguradas à pessoa com deficiência prioridade e segurança nos procedimentos de embarque e de desembarque nos veículos de transporte coletivo ${ }^{23}$.

Ainda para resguardar a acessibilidade da pessoa com deficiência e diversificar os meios de transporte a serem utilizados pelo coletivo, as frotas de empresas de táxi devem reservar $10 \%$ (dez por cento) de seus veículos acessíveis à pessoa com deficiência, vedandose a cobrança diferenciada de tarifas ou de valores adicionais pelo serviço. Similarmente, as locadoras de veículos estão obrigadas a oferecer 1 (um) veículo adaptado para uso de pessoa com deficiência, a cada conjunto de 20 (vinte) veículos de sua frota ${ }^{24}$.

A legislação brasileira de tutela assegura à pessoa com deficiência visual acompanhada de cão-guia o direito de ingressar e permanecer com o animal em todos os meios de transporte e em estabelecimentos abertos ao público, de uso público e privados de uso coletivo. Aplicando-se a todas as modalidades e jurisdições do serviço de transporte

21 Vide art.46, da Lei n.13.146, de 6 de julho de 2015.

22 Vide art.47, da Lei n.13.146, de 6 de julho de 2015.

23 Vide art.48, da Lei n.13.146, de 6 de julho de 2015.

24 Vide art.51 e art.52, da Lei n.13.146, de 6 de julho de 2015. 
coletivo de passageiros, inclusive em esfera internacional com origem no território brasileiro $^{25}$.

VII) Direito à participação na vida pública e política

A pessoa com deficiência possui o direito de votar e de ser votada, mediante a adoção de mecanismos que assegurem à consecução do direito de participação cidadã, com a garantia de que os procedimentos, as instalações, os materiais e os equipamentos para votação sejam apropriados, acessíveis a todas as pessoas e de fácil compreensão e uso, sendo vedada a instalação de seções eleitorais exclusivas para a pessoa com deficiência e sempre que necessário e a seu pedido, poderá ser concedida permissão para que a pessoa com deficiência seja auxiliada na votação por pessoa de sua escolha ${ }^{26}$.

VIII) Direito ao atendimento prioritário e por pessoal qualificado para o repasse de informações e apoio

A pessoa com deficiência tem direito ao atendimento prioritário, principalmente ao que tange a proteção e socorro em quaisquer circunstâncias, em todas as instituições e serviços públicos, mediante a disponibilização de recursos, tanto humanos quanto tecnológicos, que garantam o acesso, em igualdade de condições, com as demais pessoas, a disponibilização de pontos de parada, estações e terminais acessíveis de transporte coletivo de passageiros e garantia de segurança no embarque e no desembarque e o acesso a informações e disponibilização de recursos de comunicação acessíveis ${ }^{27}$.

Com efeito, os direitos essenciais de saúde, educação, assistência e outros legalmente determinados tão somente serão efetivados se o fator humano encontrar-se apto e qualificado ao suporte das pessoas com deficiência, com respeito e domínio da legislação pertinente de tutela.

IX) Direito à saúde e adequação dos espaços urbanos e recursos humanos imprescindíveis à efetivação de tal direito

É assegurada atenção integral à saúde da pessoa com deficiência, por intermédio do Sistema Único de Saúde - SUS, garantido acesso universal e igualitário a todos, nos moldes dos próprios preceitos constitucionais vigentes.

25 Vide art. $1^{\circ}$ da Lei $\mathrm{n}^{\circ} 11.126$, de 27 de junho de 2005, com as respectivas alterações na redação decorrentes da Lei n. 13.146, de 2015.

26 Vide art. 76 da Lei $\mathrm{n}^{\circ}$ 13.146, de 2015.

27 Vide art. 9ํa Lei ${ }^{\circ}$ 13.146; cf. art. 17 da Lei n. 13.146, de 6 de julho de 2015. 
Com relação às pessoas com deficiência, encontramos dúplice mecanismo de tutela especial: os profissionais que prestam assistência à pessoa com deficiência, especialmente em serviços de habilitação e de reabilitação, devem encontrar-se capacitados para o atendimento específico e, por outro lado, os espaços destinados ao atendimento dos serviços de saúde, tanto públicos quanto privados, devem assegurar o acesso da pessoa com deficiência, mediante a remoção de barreiras, por meio de projetos arquitetônicos, de ambientação de interior e de comunicação que atendam às especificidades das pessoas com deficiência física, sensorial, intelectual e mental ${ }^{28}$.

\section{CONSIDERAÇÕES FINAIS}

O Brasil segue firmando e incorporando ao direito pátrio os mais importantes documentos pactuados na esfera internacional. De igual modo, o país vem adotando medidas, políticas, boas práticas e corpos normativos de resguardo aos essenciais direitos dos coletivos em situação de vulnerabilidade e risco de exclusão social, como as pessoas com deficiência.

Contudo, permissa venia, há significativos interrogantes que insistem em permanecer ao descoberto: se por um lado há vários aspectos que não receberam a abordagem devida ou simplesmente passaram in albis, em meio a tantos outros temas de similar relevância para as pessoas com deficiência, por outro lado, em muitas situações vivenciadas em solo pátrio, a realidade fática distancia-se das normas, políticas, programas e medidas de tutela específica, seja por falta de recursos, de compromisso, de gestão ou de qualificação das pessoas responsáveis pela ativação dos instrumentos de tutela.

De esta forma, os preceitos que norteiam o desenvolvimento humano sustentável clamam por modelos pautados no amplo exercício das aptidões humanas, em suas carências e perspectivas, edificando paradigmas multidimensionais para a interação de valores sociais, ambientais, ideológicos e políticos. Com efeito, deve-se conceber o ser humano como protagonista em todo e qualquer plano de desenvolvimento integral, centrando-se, pois, na adequada satisfação das necessidades imperantes.

Entre equívocos e acertos, vaticinamos que a ordem prevalecente ostente as concepções e os padrões mais favoráveis para sanar às agruras que assolam os preceitos de igualdade, liberdade, segurança e solidariedade, resultando na edificação de pilares reforçados para a consecução das primícias da sustentabilidade. E, para tanto, a educação e a transmissão

28 Cf. art. 18 e art.25 da Lei n. 13.146, de 6 de julho de 2015. 
transgeracional dos ideários de justiça, equidade e igualdade como reflexos da cidadania plural é a baliza mestra para a (re)construção e orientação das propostas urbanísticas vindouras.

\section{REFERÊNCIAS}

BÉLGICA. Observatoire ASPH de la Personne Handicapee. Etude 2011. Vie affective, relationnelle et sexuelle in institution. Solidaris Mutualité. 52 páginas. Disponível em: http://www.asph.be/ASPH/Analyses-et-etudes/ASPH-etudes-2011.htm.

BRASIL. VI Relatório Nacional Brasileiro. Convenção para a Eliminação de todas as formas de Discriminação contra as Mulheres (CEDAW) - Organizações das Nações Unidas. Secretaria Especial de Políticas para as Mulheres. Brasília, 2008, página 173. Disponível em: http://www.sepm.gov.br/publicacoes-teste/publicacoes/2008/livrocedawweb.pdf.

BRASIL. Ministério do Planejamento, Orçamento e Gestão. Instituto Brasileiro de Geografia e Estatística-IBGE. Diretoria de Pesquisas. Coordenação de População e Indicadores Sociais. Pesquisa de Informações Básicas Municipais. Perfil dos Municípios Brasileiros 2009. Rio de Janeiro, 2010. Relatório MUNIC 2009.

BRASIL. Programa Nacional de Direitos Humanos (PNDH-3)/Secretaria de Direitos Humanos da Presidência da República. Brasília: SDH/PR, 2010.

BRASIL. Decreto $\mathrm{n}^{\circ}$ 7.612, de 17 de novembro de 2011. Institui o Plano Nacional dos Direitos da Pessoa com Deficiência - Plano Viver sem Limite.

BRASIL. Resoluções aprovadas na $3^{a}$ Conferência Nacional de Políticas para as Mulheres. Autonomia e igualdade para as mulheres. Realizada em Brasília, de 12 a 15 de dezembro de 2011. Secretaria de Políticas para as mulheres. Disponível em: http://www.sepm.gov.br.

BRASIL. Portaria $n^{\circ}$ 610, do Ministério das Cidades, de 26 de dezembro de 2011, publicada no Diário Oficial da União $\mathrm{n}^{\circ} 248$, de 27 de dezembro de 2011, dispõe sobre os parâmetros de priorização e o processo de seleção dos beneficiários do Programa Minha Casa, Minha Vida - PMCMV.

GORDILLO, Vanessa Cordero. Igualdad y No Discriminación de las Personas con Discapacidad en el Mercado de Trabajo. "Colección Laboral" 194. Valencia: Tirant Lo Blanch, 2011.

HRW. Human Rights Watch. "As if We Weren't Human": Discrimination and Violence Against Women with Disabilities in Northern Uganda., agosto 2010. Disponível em: http://www.hrw.org/node/92611.

IGLESIAS PADRÓN, Marita. The nature of violence against disabled people. Em: Violence Against People With Disabilities: Seminar Proceedings. National Disability Authority, Dublin, 29 de novembro de 2004. Disponível em: http://www.nda.ie/cntmgmtnew.nsf/0/BE967D49F3E2CD488025707B004C4016?. 
. Relatório Violencia y mujer con discapacidad. Asociación Iniciativas y Estudios Sociales. 1998. Informe elaborado como parte das ações desenvolvidas no marco do Projeto METIS sobre Violencia y Mujer con Discapacidad. Projeto METIS foi realizado pela Associação I.E.S. Com o amparo da Iniciativa DAPHNE da Comissão da Unão Europeia (19971998). Disponível em inglês e espanhol em: http://www.asoc- ies.org/violencia/index.html.

INWWD. International Network of Women With Disabilities. Relatório Violência contra Mulheres com Deficiência. Tradução espanhol: Marita Iglesias; Rosa Chavez. Grupo de discussão sobre violência, outubro de 2010, 17 páginas. Disponível em: http://www.internationaldisabilityalliance.org/advocacy-work/the-international-network-ofwomen-with-disabilities-inwwd/.

NEWTON, Paulla Christianne da Costa. Empleo y sexismo: medidas de protección e inserción sociolaboral de las mujeres víctimas de violencia de género em el seno de la pareja. Valencia: Tirant Lo Blanch, 2011.

OMS (Organização Mundial da Saúde). Informe Mundial sobre la Discapacidad. Resumen. Malta, 2011.

ONU. Convenção sobre os Direitos das Pessoas com Deficiência e seu Protocolo Facultativo, homologados pela Assembleia das Nações Unidas em 13 de dezembro de 2006, na Sede das Nações Unidas em Nova York (A/RES/61/106).

PADRÓN, Marita Iglesias. Relatório Violencia y mujer con discapacidad. Asociación Iniciativas y Estudios Sociales. 1998. Informe elaborado como parte das ações desenvolvidas no marco do Projeto METIS sobre Violencia y Mujer con Discapacidad. Projeto METIS foi realizado pela Associação I.E.S. Com o amparo da Iniciativa DAPHNE da Comissão da União Europeia (1997- 1998). Disponível em inglês e espanhol em: http://www.asocies.org/violencia/index.html. Acesso em: 19 de maio de 2014. 